\title{
Fractographic characterization of fatigued zirconia dental implants tested in room air and saline solution
}

\author{
Shemtov-Yona, K ; Özcan, M ; Rittel, D
}

\begin{abstract}
The identification of the fractographic signature of monotonic and fatigue loads in ceramic materials is far from being straightforward, as embodied in a subtle blend of cleavage (trans.) and intergranular fracture. As of today, most fractographic analyses are carried out at low/middle magnifications. In this research, we have systematically examined commercial zirconia dental implants that were fractured in the laboratory under monotonic overload and random spectrum fatigue, thus generating a bank of well controlled fractured reference specimens. The tests were carried out in both room air and in $0.9 \%$ saline solution. Our results show that it is difficult to distinguish static fracture in room air from saline solution. By contrast, spectrum fatigue in either air or saline solution, results in observable differences from dominantly trans. to a mixed trans.-intergranular fracture at the origin of the crack (first $60 \mathrm{~m}$, as an upper bound value). Further down the unstable propagation zone, an increased tendency for intergranular fracture is observed, which seems to be exacerbated by the saline solution when compared with room air. Overall, it is observed that static and fatigue fractures can be distinguished from one another. It is believed that this fractographic database will serve as a reference for future analyses of broken ceramic dental implants and identification of their fracture mechanism.
\end{abstract}

DOI: https://doi.org/10.1016/j.engfailanal.2018.10.020

Posted at the Zurich Open Repository and Archive, University of Zurich

ZORA URL: https://doi.org/10.5167/uzh-183014

Journal Article

Accepted Version

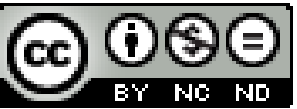

The following work is licensed under a Creative Commons: Attribution-NonCommercial-NoDerivatives 4.0 International (CC BY-NC-ND 4.0) License.

Originally published at:

Shemtov-Yona, K; Özcan, M; Rittel, D (2019). Fractographic characterization of fatigued zirconia dental implants tested in room air and saline solution. Engineering Failure Analysis, 96:298-310.

DOI: https://doi.org/10.1016/j.engfailanal.2018.10.020 


\title{
Fractographic characterization of fatigued zirconia dental implants tested in room air and saline solution
}

\author{
K. Shemtov-Yona1*, M. Özcan2 and D. Rittel1 \\ 1Faculty of Mechanical Engineering, Technion, 32000 Haifa, Israel \\ ${ }_{2}$ Center for Dental and Oral Medicine, University of Zurich, CH-8032, Zurich, Switzerland \\ Declarations of interest: none
}

\begin{abstract}
The identification of the fractographic signature of monotonic and fatigue loads in ceramic materials is far from being straightforward, as embodied in a subtle blend of cleavage (trans.) and intergranular fracture. As of today, most fractographic analyses are carried out at low/middle magnifications.

In this research, we have systematically examined commercial zirconia dental implants that were fractured in the laboratory under monotonic overload and random spectrum fatigue, thus generating a bank of well controlled fractured reference specimens. The tests were carried out in both room air and in $0.9 \%$ saline solution.

Our results show that it is difficult to distinguish static fracture in room air from saline solution. By contrast, spectrum fatigue in either air or saline solution, results in observable differences from dominantly trans. to a mixed trans.-intergranular fracture at the origin of the crack (first $60 \mu \mathrm{m}$, as an upper bound value). Further down the unstable propagation zone, an increased tendency for intergranular fracture is observed, which seems to be exacerbated by the saline solution when compared with room air. Overall, it is observed that static and fatigue fractures can be distinguished from one another.

It is believed that this fractographic database will serve as a reference for future analyses of broken ceramic dental implants and identification of their fracture mechanism.
\end{abstract}

Keywords: Zirconia, dental implants, fatigue, monotonic overload, fractography, SEM

*Corresponding author: kerenrst77@gmail.com 


\section{INTRODUCTION}

Fractographic analysis is the most reliable way to identify unambiguously the fracture mechanism(s) that led to structural failure. It is used in order to identify the structural or the material weak points, and in the spirit of the "safe-life approach", prepare for the damage and avoid it. The analysis includes examination of the fracture surface and identification of the failure mechanism(s). For structures made of metals and alloys, each failure mechanism has a well-defined "signature", observed in the scanning electron microscope. In most cases, one can reach a clear conclusion as to the operation of e.g. monotonic overload vs. fatigue fracture, or whether some deleterious environment was involved, leading to (stress) corrosion damage $[1,2]$.

The situation is much different when composite or brittle (e.g. ceramic) materials are involved. Because of the brittle nature of these materials and their unique mechanical properties, the commonly suspected failure mechanism is monotonic overload. Considering specifically ceramic materials, the literature comprises a lot of useful information, as e.g. in [3,4], but most of it concerns the macroscopic details of the fracture surface such as the presence of hackles, defects and river lines pointing to the crack origin and its direction of propagation. Those observations are essentially relevant to monotonic overload fracture and the related unstable crack growth.

From the literature, it appears that the dominant feature of the fractographic analysis of ceramics emphasizes those macroscopic features whether in laboratory studies or failure analyses [5-10], perhaps because of the operation of only two failure micromechanisms, namely intergranular and transgranular. A summary of the recommended fractographic practice can be found in [11], in which optical and low magnification identification procedures are thoroughly exposed. Additional work can be found in which the fracture surfaces are essentially analyzed at low to medium magnifications, e.g. [12], for the failure analysis of a monolithic zirconia implant, or e.g. in [13-16].

When brittle materials are used in structural applications, like zirconia or alumina for dental applications, service loads are generally cyclic and often involve a specific intra-oral environment. Consequently, is important to characterize the fracture behavior under cyclic loading or varying load amplitude (spectrum). Although many studies on fatigue of ceramics have been performed, most of them analyzed and characterized their fatigue behavior, crack propagation and crack velocity in terms of $\mathrm{da} / \mathrm{dN}$ or $\mathrm{da} / \mathrm{dt}$ curves [17-20]. In parallel, studies characterizing the fatigue failure micromechanisms are still scarce. 
From a mechanical point of view, important information can be found regarding basic cyclic damage mechanisms in [21], emphasizing intergranular cracking, or in [22] showing a major difference between monotonic overload and cyclically induced fracture through the presence of multiple debris in the latter case. And since the unique characteristics of those brittle materials are likely to involve local transitions from mode I to mode II crack propagation, one should mention here the work of Landes [23] who reports intergranular (pullout) fracture for mode I, complemented again by the presence of debris for mode II. Likewise, this work reports the usual mix of inter and trans-granular fracture with a quantitative difference, namely $6 \%$ transgranular in mode I vs. $23 \%$ in mode II.

The environmental effect of stress corrosion under static and cyclic loading is known for some types of ceramics. Okabe et al. [24] studied the fatigue fracture behavior of zirconia and alumina in water. The study showed that the time to fracture of fatigue tests gets reduced with respect to that in air. The fracture surfaces showed mixed intergranular and transgranular cracking, which was dominantly intergranular for zirconia tested in water. The authors explained the observed result by a mechano-chemical reactions between the water and zirconia leading to separation and cracking at grain boundaries.

In that respect, and considering the limited fractographic information at high magnifications, there is no well accepted distinction between those two failure modes and their identification. To a point that one will often find mentions of possible fatigue, without any clear identification as in [25].

As of today, it appears that there are no (or very few) well controlled and systematic laboratory failure experiments in which the subsequent fractographic analysis has been conducted in depth. This of course would necessitate more emphasis on microscopic details, such as the above-mentioned debris, trans. vs. intergranular fracture and others, that can only be identified at relatively high magnifications. Such orderly information is currently missing in order to clearly distinguish (if possible) fatigue from monotonic fracture first, then ascertaining the involvement of a fluid environment, and then use this information for failure analysis purposes, thereby minimizing guesswork, as noted e.g. in [26].

Ceramic dental implants are made of partially stabilized zirconia. Those implants are archetypes of biomedical structures that are subjected to continuously varying loads, intraoral atmospheres and mastication frequencies. Therefore we chose to examine the fracture surfaces of ceramic dental implants as a typical structural ceramic device, and to identify the fracture mechanism(s) that led to structural failure. The main aim is to provide a clear account of the monotonic and the cyclic fracture micromechanisms, their similarities and differences. 
This paper reports on the fractographic analysis of Y-TZP dental implants that were systematically broken monotonically and also fatigued in the laboratory, using the random spectrum loading technique ([27], briefly detailed in the sequel), when tested in room air and in $0.9 \%$ saline solution at room temperature. The mechanical results and their significance are summarized in another paper, so that only the relevant elements will be mentioned here.

The paper is organized as follows: we first give a brief account of the testing technique and the investigated specimens. Next, we report a small fracture mechanics based calculation of the critical flaw size, given the Y-TZP fracture toughness and specimen dimensions, such as to provide an estimate of the size over which the microscopic investigation must concentrate. We detail next the mechanical properties and relevant information for each investigated specimen, to be followed by the most characteristic fractographic pictures and the information they contain. Those results are discussed next, followed by the conclusions of this work.

\section{MATERIALS and METHODS}

Commercial dental implants, made of Y-TZP ceramic (composition listed in Table A1, Appendix 1) were cemented in steel cylindrical jackets (Figure 1). The specimens were then loaded at an angle of $30^{\circ}$ ( as recommended in [28]) with respect to the vertical axis of an MTS servo-hydraulic machine operated in displacement control for the monotonic overload tests and in load control for random spectrum fatigue testing. All the tested specimens were mounted identically and had their first thread exposed out of the jacket.

The fatigue testing consisted of random spectrum loading, a technique that has been exposed in detail previously $[27,29,30]$ so that it will only be briefly detailed here. The main idea is to apply random loading cycles in a range of selected loads $(\mathrm{P})$ from 0 to $\mathrm{P}_{\max }$, at frequencies that vary from $0 \mathrm{~Hz}$ (pause of variable duration) up to $3 \mathrm{~Hz}$. This concept is adapted from classical structural testing concepts that are used in aeronautics or seismic engineering. The spectrum is deemed to replicate to some extent the randomness of mastication. The maximum load was set to $P_{\max }=600 \mathrm{~N}$, as discussed next. Note that the tests were carried out at room temperature in room air and in $0.9 \%$ saline solution, and all were carried out until failure (fracture). Fracture surfaces were then collected for microscopic examination. The outcome of such a test is that for a group of tested implants, one comes up with an average (or median) longevity (time or number of cycles until fracture) and its standard deviation, if necessary. Such a functional outcome allows, among other things, for a quick comparison between various batches that could differ in every aspect, ranging from material to geometry and atmosphere, or 
combinations thereof. Here it is important to emphasize that whatever group characteristics are considered, all groups undergo the one and same spectrum loading sequence.

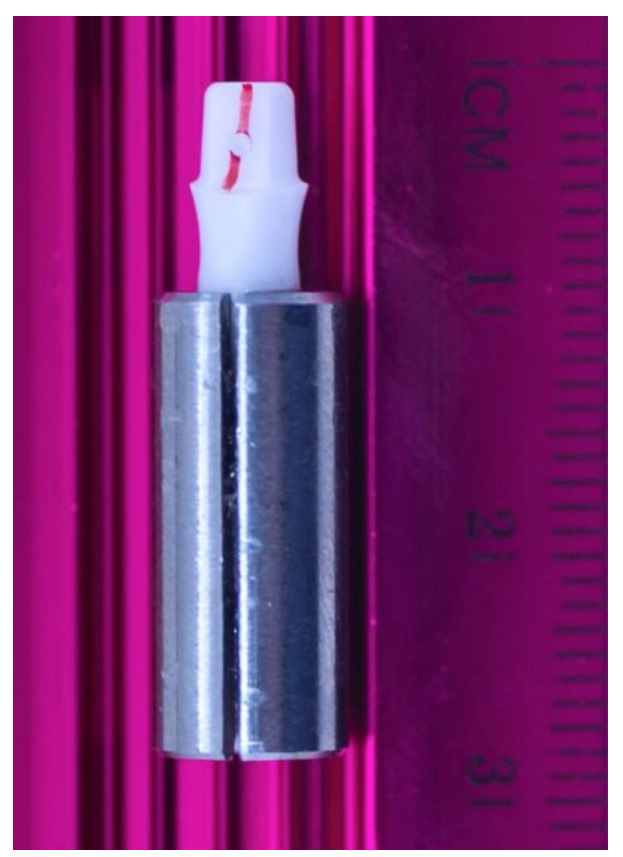

Figure 1: Ceramic dental implant mounted in the cylindrical steel jacket. The red marker line indicates the side to be bent during loading

Scanning electron fractography was carried out on both a QUANTA 200 (Phillips) SEM and a Mira 3XMH Tescan high resolution SEM. Prior to examination, all the fracture surfaces were rinsed and cleaned ultrasonically in pure ethyl alcohol, followed by sputter-coating with a very thin layer of gold palladium.

\section{RESULTS}

\subsection{Quasi static tests}

A total of 5 specimens were tested in room air and 4 in saline solution. The bending fracture strength in room air was $802 \pm 107 \mathrm{~N}$ and $639 \pm 51 \mathrm{~N}$ in saline solution. While the limited sample size precludes any accurate statistical analysis, it appears that the saline solution decreases immediately the bending strength of the implants by about $20 \%$. Additional data can be found in Appendix 2 (Table A2). As mentioned, the maximum load that was set as an upper limit in the random spectrum tests to $P_{\max }=600 \mathrm{~N}$.

\subsection{Fatigue tests}


A detailed account of the fatigue tests procedure is reported elsewhere. For a sample size of 15 specimens per group, the individual times to fracture were analyzed statistically. A statistically significant difference (Ranksum test) was found between the lifetime of zirconia tested in room air and in $0.9 \%$ saline solution ( $\mathrm{p}=0.0144)$. Namely, the longevity of the roomair group was longer than that of the saline group (average time $5131 \pm 5527$ s, median 2738 s, vs. average time $2032 \pm 2912$, s and median 1449 s, respectively).

Given that the elapsed time to fracture is linearly related to the number of load cycles, the number of cycles (not time) and the spectrum fracture load were recorded for each group of specimens, of which the representative subset for which fractographic results are shown here. Detailed data is reported in Table A2 (Appendix 2)

The statistical analysis (Ranksum test) of the spectrum fatigue fracture loads of each group showed no significant difference $(\mathrm{p}=0.3484)$. The median fatigue fracture load is $552 \mathrm{~N}$ in room air vs. 538 in $0.9 \%$ saline solution group.

\subsection{Critical crack size estimation}

A finite element model was devised to estimate the critical crack length of a zirconia cylinder, of similar dimensions to a typical implant with the same boundary conditions and a straight crack located in the constrained area (see details in Appendix 3). The idea is to get an estimate of the critical crack size and associated failure micromechanism corresponding to the measured fracture load, given the (representative) fracture toughness of the zirconia $\left(\mathrm{K}_{\mathrm{Ic}}=5.5 \mathrm{MPa} \mathrm{m}_{1 / 2}\right)$. For an applied load of $600 \mathrm{~N}$ applied at $30^{\circ}$ with respect to the implant axis, given a diameter of $3.5 \mathrm{~mm}$ and exposed length of $12.5 \mathrm{~mm}$, respectively, the critical crack/flaw size is of the order of $59 \mu \mathrm{m}$.

\subsection{Specimens for SEM analysis}

Table A2 lists all the relevant details of the specimens that are shown in this report, noting that all the specimens of each test group were examined. The subgroup of specimens for which the fractographic analysis is reported here is representative.

\subsection{Fractographic analysis}

In the forthcoming analysis, we will first characterize each group individually (dry, saline, quasi-static and spectrum), followed by an inter-comparison. We will start with the 
macroscopic features of the fracture in the area of the crack origin, followed by higher magnification scrutiny of the failure micromechanisms.

\section{Surface of the implants}

Figure 2 shows low magnification pictures of the (outer) surface of various implants. One can notice the present of several crack-like flaws, whose origin may be related to the manufacturing and/or handling of the implant. Such flaws can act as native stress raisers, adding to the statistical dispersion of the fatigue performance of the implants.
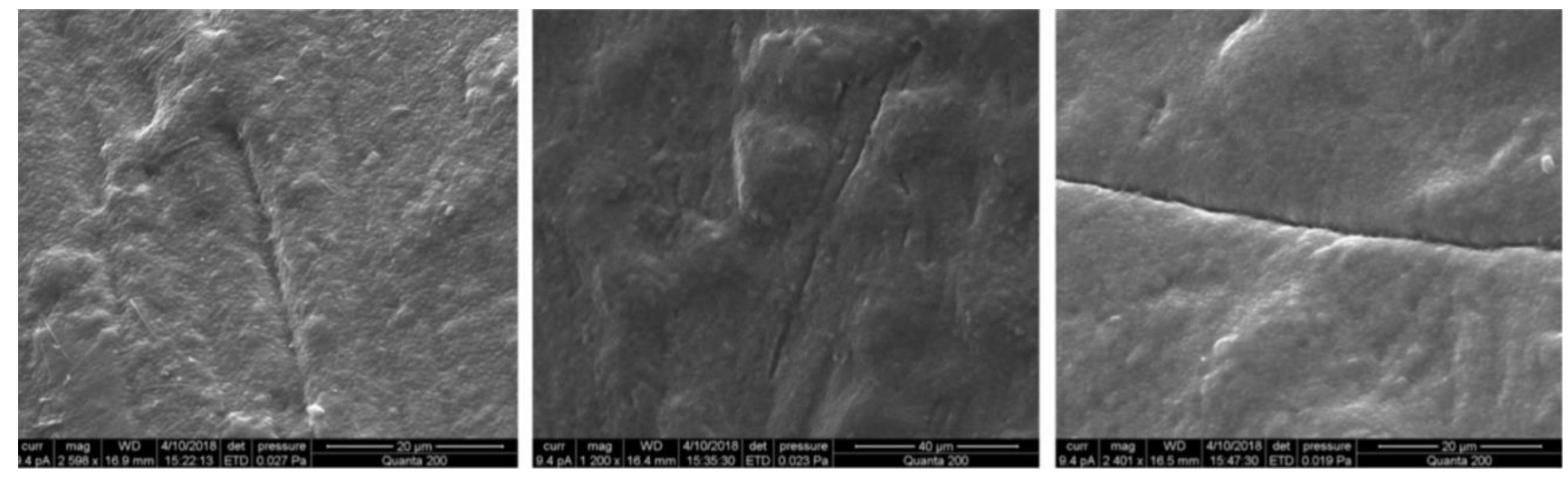

Figure 2: Surface morphology of various implants (fractography not reported here).

\section{Fracture origin - low magnification}

Figure 3 is a macroscopic picture of a typical fracture surface. One can see the surface is relatively flat. The crack origin is marked (approximately $59 \mu \mathrm{m}$, see appendix) with the addition of $200 \mu \mathrm{m}$ and $600 \mu \mathrm{m}$ locations. The fractographs shown in sequel were taken from the marked generic locations. 


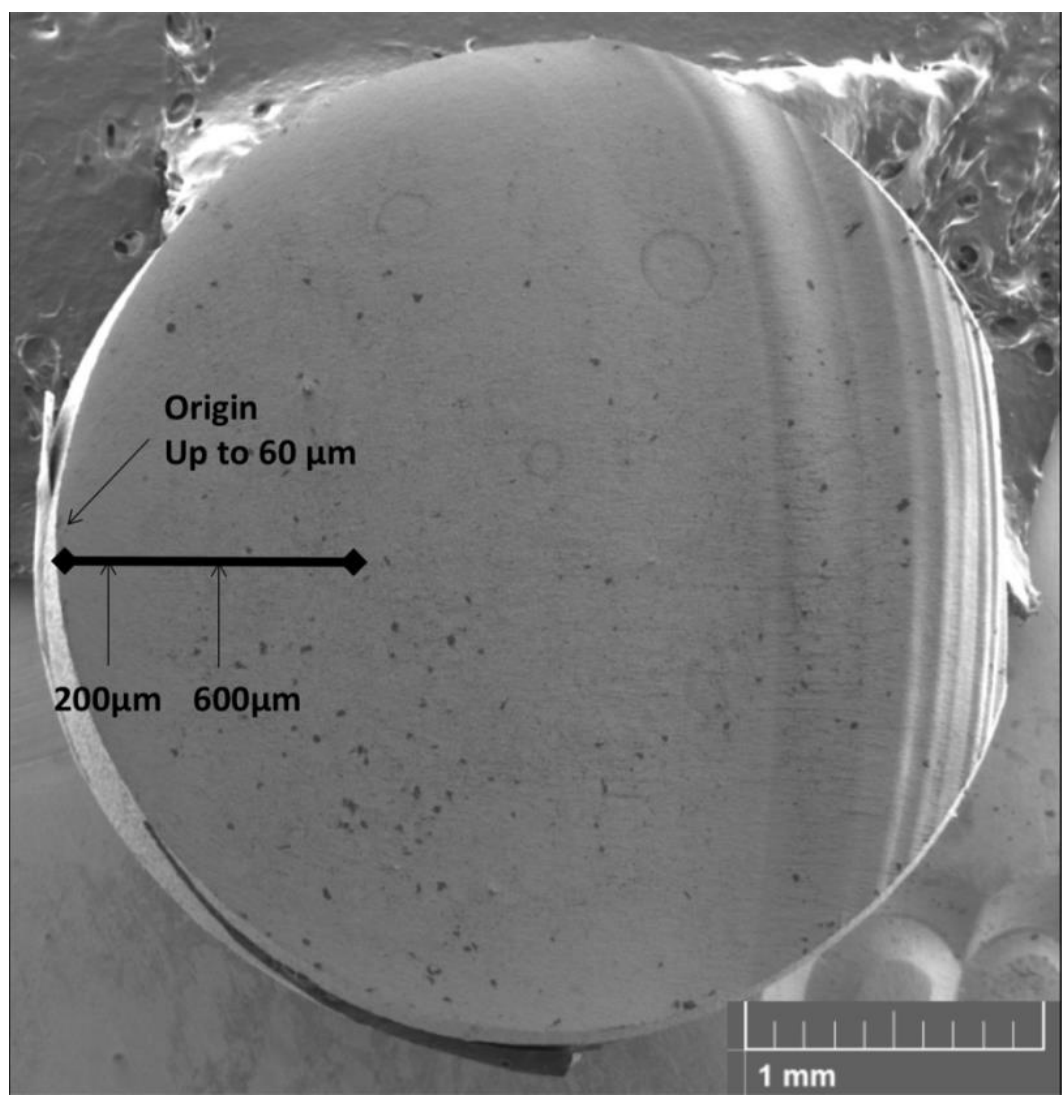

Figure 3: Macroscopic fracture surface with typical observation distances from the implant's outer surface.

The origin of the fractures of selected implants is shown in Figure 4. The field of view is relatively large, roughly $200 \times 100 \mu \mathrm{m}$. Irrespective of the loading mode and atmosphere, this origin is clearly identified on each picture and outlined by river lines that point to the origin, as typical for brittle materials.

It should be noted that throughout the work, emphasis was not put of the precise identification of the crack's origin in terms of initial flaw or alike, but rather on the identification of the region of crack origin as a whole to further characterize the fracture micromechanism. 


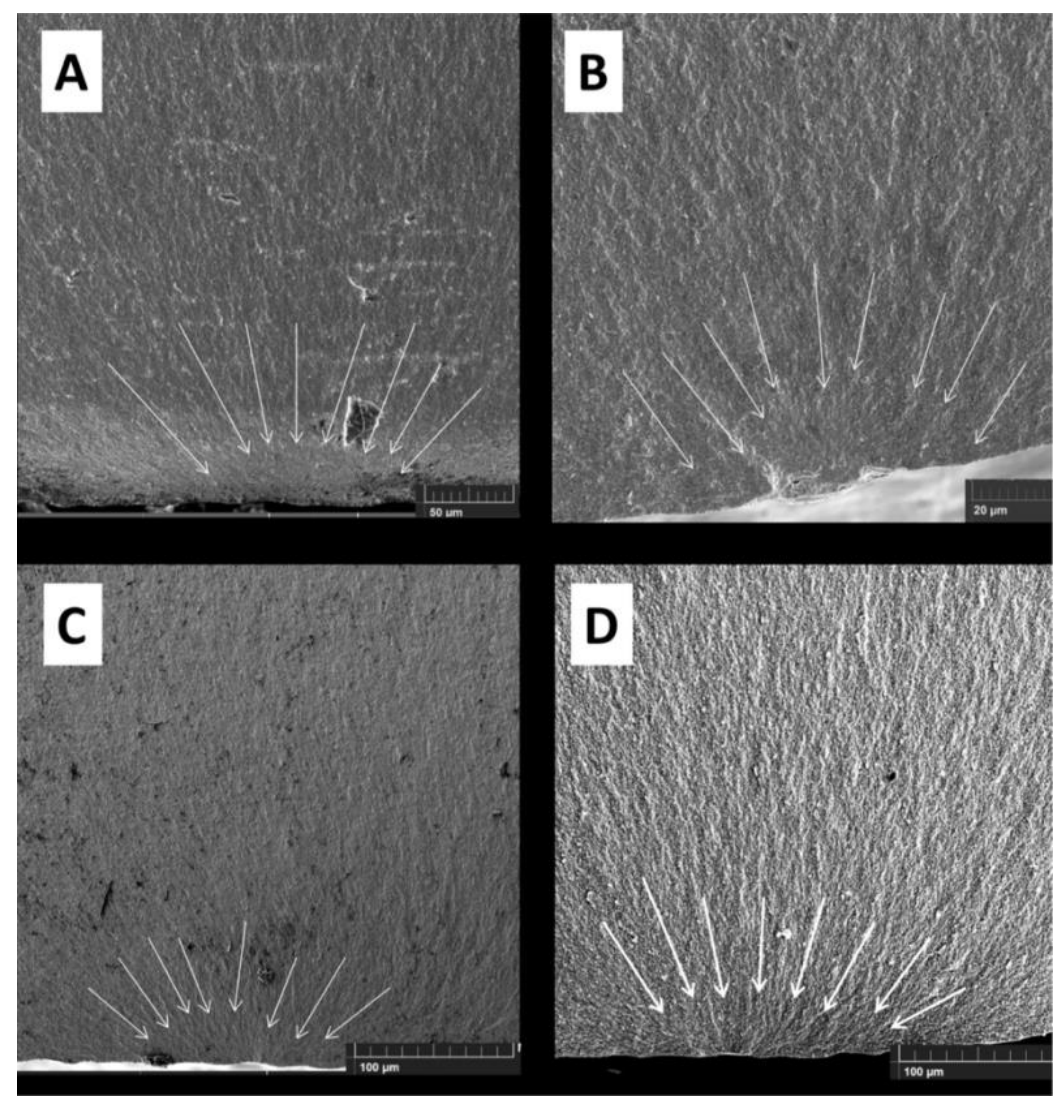

Figure 4: Macroscopic origin. A: C3 static-dry, B: C36-static saline, C: C16-spectrum dry, and D: C45-spectrum saline. The arrows indicate hackles pointing to the crack origin.

Fracture origin - higher magnification

Additional information can be retrieved by examination of the crack's origin at higher magnifications, as shown in Figure 5. 


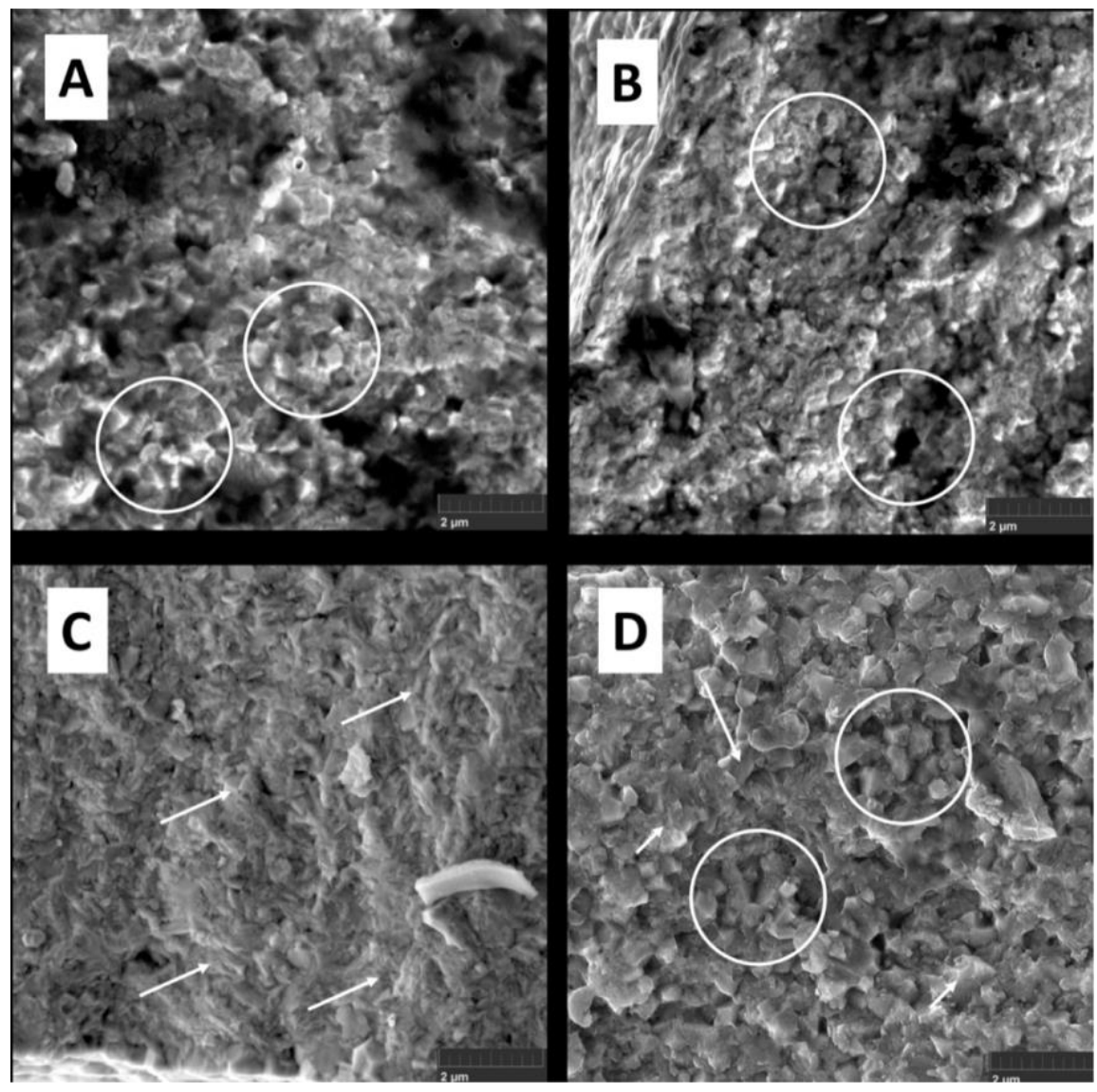

Figure 5: Fracture origin. A: C1-static dry, B: C38 static-saline, C: C16-speectrum dry, and D: C51 spectrum saline. The circles indicate intergranular and the arrows transgranular fracture.

In the origin region, both room-air and saline solution, statically broken specimens exhibit dominantly transgranular with some intergranular fracture, evidenced by cavities (pulled-out grains indicated by white circles), as shown in Figure $5 \mathrm{~A}$ and B. For the fatigue specimens, the topography of the fracture surface of the room-air specimen is essentially transgranular, (Figure $5 \mathrm{C}$ ), while for the saline one, it is a mixture of inter. and transgranular fracture, (Figure $5 \mathrm{D})$.

Fracture 200 micron away from the edge of the specimen

Examination of the fracture surface at about $200 \mu \mathrm{m}$ from the specimen's edge reveals details about the onset of unstable crack propagation outside the origin area (Figure 6). 


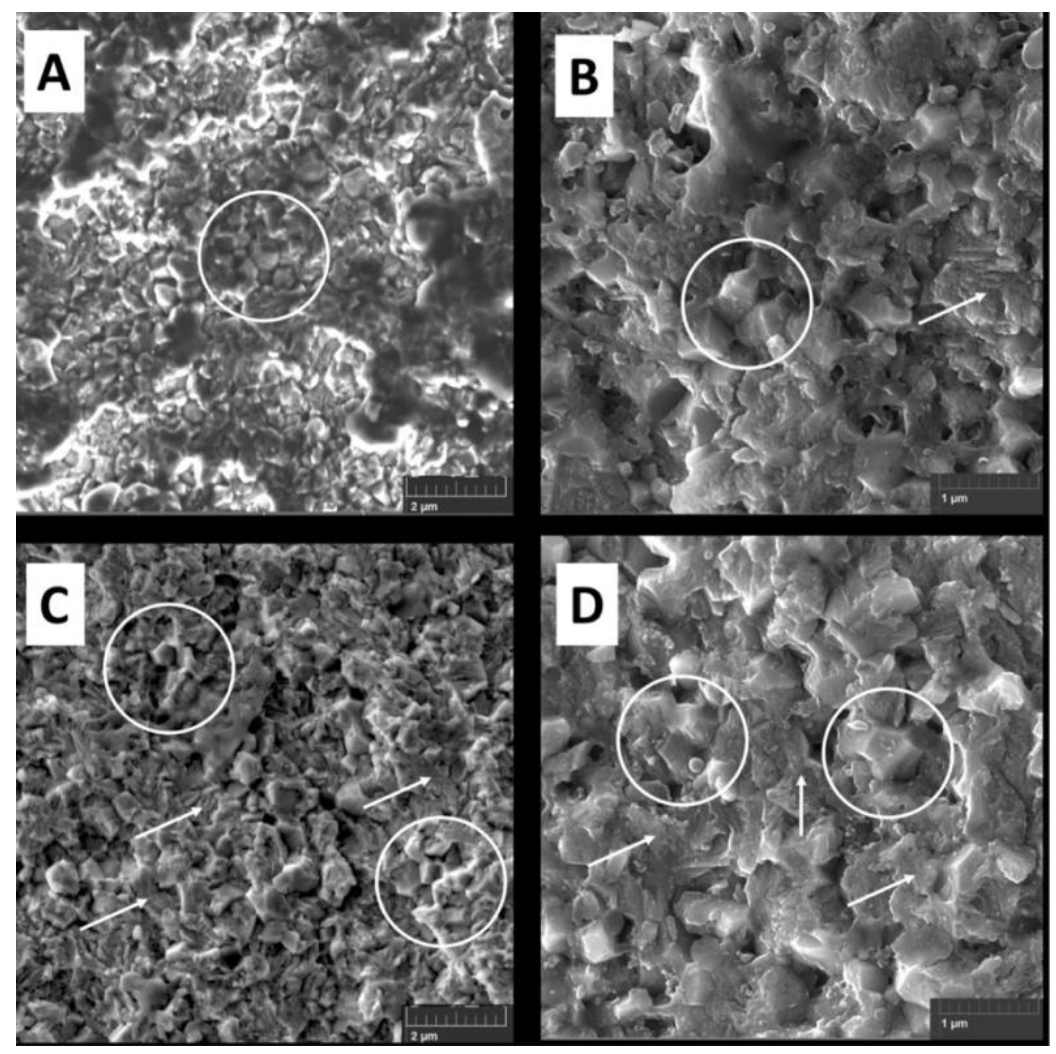

Figure 6: Fracture surface at about 200 micron away from the fracture origin (implant's edge). A: C1-static dry, B: C36-static saline, C: C16-spectrum dry, and D: C39-spectrum saline. The circles indicate intergranular and the arrows transgranular fracture.

Here too, both room-air and saline solution, statically broken specimens exhibit a mixed mode of inter. and transgranular fracture (Figure $6 \mathrm{~A}$ and B). The same observation applies to the spectrum loaded specimens (Figure $6 \mathrm{C}$ and D).

Fracture 600 micron, or further away or from the edge of the specimen

Figure 7 shows the typical topography of the fracture surfaces of fully developed and unstable cracks. 


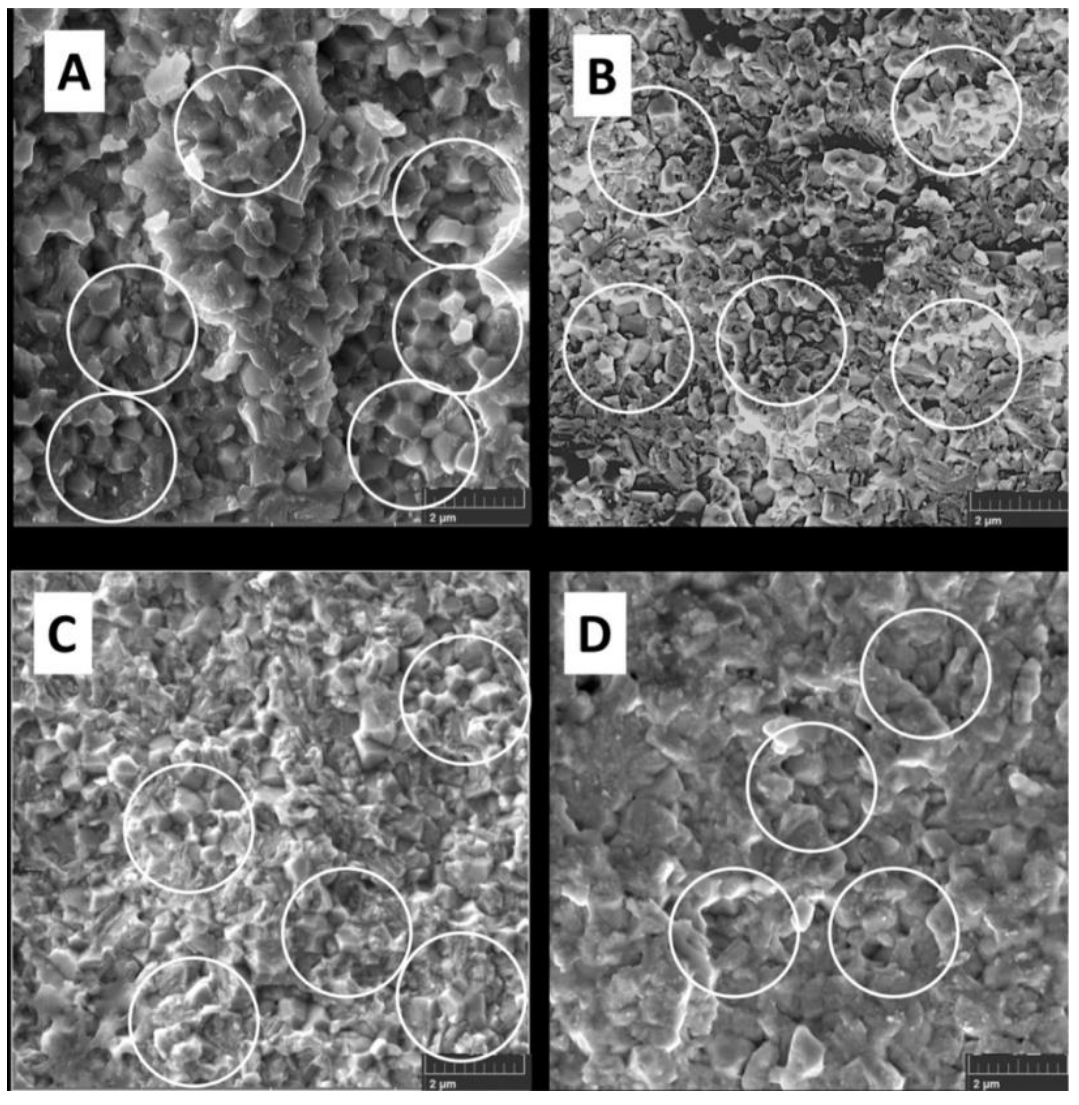

Figure 7: Fracture surface at about $600 \mu \mathrm{m}$ or more from the fracture origin (implant's edge). A: C3-static dry, B: C38-static saline, C: C16-spectrum dry, and D: C51-spectrum saline. The circles indicate intergranular fracture.

Both room-air and saline solution, statically broken specimens, exhibit dominantly intergranular fracture with interspersed transgranular (Figure $7 \mathrm{~A}$ and $\mathrm{B}$ ). The same applies to the spectrum-loaded specimen tested in room air (Figure $7 \mathrm{C}$ ), while that tested in saline solution is dominantly intergranular with minimal presence of transgranular (Figure 7 D).

\section{More on inter. and transgranular fracture}

Figure 8 shows a high magnification of the fracture surface, aimed at illustrating intergranular and transgranular fracture. 


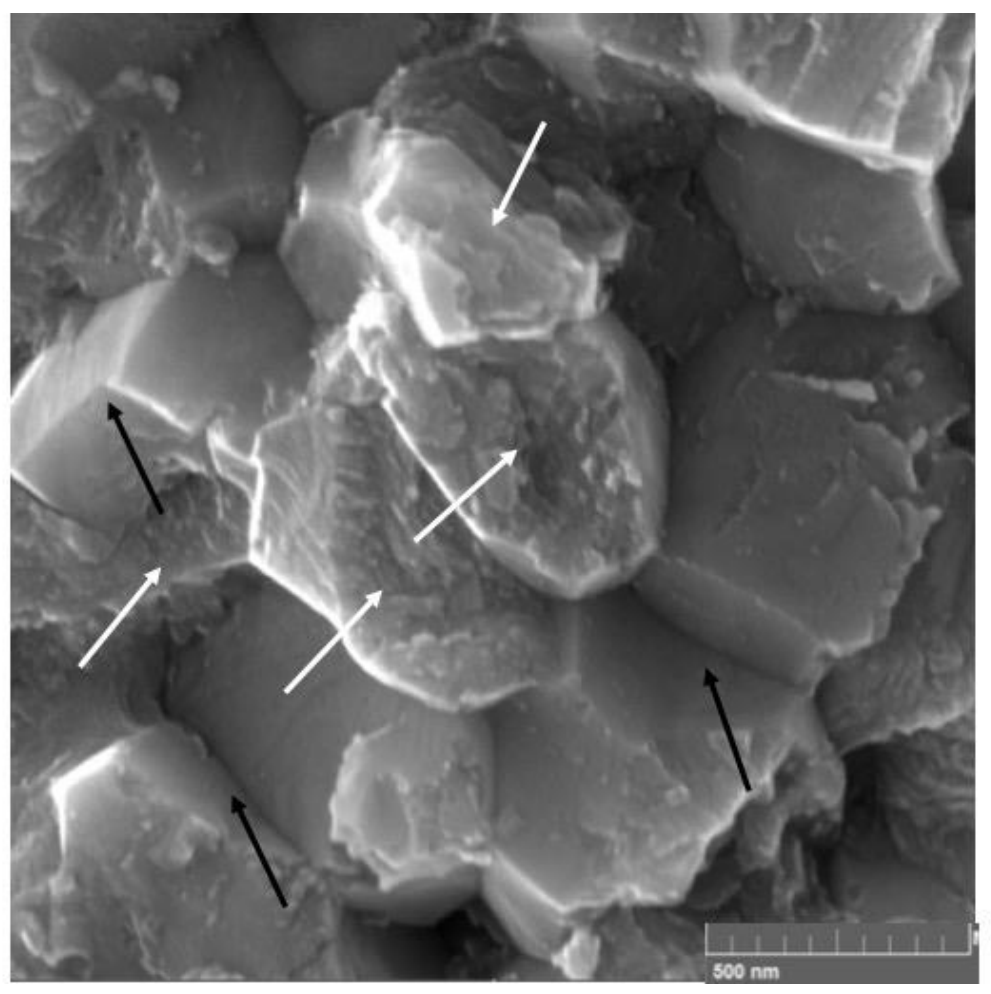

Figure 8: Intergranular (black arrows) and transgranular (white arrows) fracture

\section{Fractographic summary}

A summary of the observed fracture micromechanisms is given in Table 1.

\begin{tabular}{|c|c|c|c|}
\hline & ORIGIN & $200 \mu \mathrm{m}$ & $\geq 600 \mu \mathrm{m}$ \\
\hline Static-room air & $\mathrm{T}(\mathrm{I})$ & $\mathrm{I}-\mathrm{T}$ & $\mathrm{I}(\mathrm{T})$ \\
\hline Static-saline & $\mathrm{T}(\mathrm{I})$ & $\mathrm{I}-\mathrm{T}$ & $\mathrm{I}(\mathrm{T})$ \\
\hline Spectrum- room air & $\mathrm{T}$ & $\mathrm{I}-\mathrm{T}$ & $\mathrm{I}-\mathrm{T}$ \\
\hline Spectrum- saline & I-T & I-T & I(T) \\
\hline
\end{tabular}

Table 1: Summary of the observed fracture micromechanisms for the different tests. $\mathrm{T}$ and I stand for transgranular and intergranular, respectively. I-T means balanced mechanisms while $\mathrm{T}(\mathrm{I})$ indicates dominant transgranular, and $\mathrm{I}(\mathrm{T})$ dominant intergranular.

\section{DISCUSSION}

This study presents a systematic identification of the fracture surfaces of ceramic bio-structures that failed under well controlled and defined conditions of random spectrum loading. The main outcomes of the study could therefore be applied in future failure analyses.

The first observation that comes out of the results is that whatever the loading mode and the atmosphere, the identification of the fracture origin is rather straightforward, and a potential 
source for cracking initiation may be related to the presence of microscopic surface scratches or other geometrical flaws.

The macro-fractographic examination cannot really discriminate between the various combinations of loading modes and atmospheres unless higher magnifications are employed. It should be noted in passing that this situation is quite different from that characteristic of metals, for which the presence of a distinct area, e.g. delineated by crack arrest lines, will always indicate the operation of a time-dependent fracture mechanism, to be contrasted with a "uniform" topography that is indicative of a single monotonic overload.

The problem is further complicated by the grain size of the Y-TZP which, as can be seen in the various fractographic pictures, is of the order of $200 \mathrm{~nm}$. Such a grain size makes the identification of the failure mechanisms delicate and requires high magnifications at high resolution. The nanometric grain size confers additional importance to the grain boundaries, so that the observations reported in this work might have been different for larger grain sizes. The same observation applies to the potential influence of the simulated intraoral atmosphere in the case of preferential grain boundary attack.

Another important point to note is that of the critical crack size and the crack propagation mode. The notion of the critical crack size, of the order of $59 \mu \mathrm{m}$, is only relevant for the fatigue specimens. This length is to be considered as an upper bound since the actual implant geometry contains stress-raisers so that the actual critical crack size may be shorter. In those specimens, stable fatigue crack growth is expected to occur over that length, followed by unstable growth. By contrast, the quasi-static fracture tests cause unstable crack propagation from its very onset. Therefore, irrespective of the loading mode, it appears that special emphasis must be put on the first few microns in the vicinity of the crack origin, which necessitates high magnifications. Therefore, two main questions arise, namely:

1. Can we distinguish fatigue from monotonic fracture?

2. Has the saline environment its distinct signature?

Table 1 and the corresponding figures show that all stages of the static crack initiation and subsequent propagation are in fact characterized by the same micro-fractographic features, at the various stages of the growth process, namely inter and transgranular fracture. This applies irrespective of the test atmosphere, so that quasi-static fracture does not bear a characteristic signature of the test medium, even if a gradual transition from dominant transgranular to dominant intergranular fracture is observed. This transition may be related to the fact that the surface roughness and the stress-intensity factor $(\mathrm{K})$ increase as the crack accelerates on its way to final fracture, as reflected in the terminology of amorphous materials (the so-called 
mirror-mist-hackles mechanism) [31,32]. However, roughness cannot be ascribed preferentially to inter. or transgranular fracture. By contrast, spectrum testing yields characteristic features that differentiate it with respect to the test atmosphere and also with respect to the loading mode. This could result from the fact that under spectrum loading conditions, the material experiences much longer exposures to the fluid than under quasi-static fracture, probably analogous to real-life situations.

Examination of the topography at relatively large distances may prove delicate, but one can note again the inter-transgranular vs. dominantly intergranular nature of the fracture surfaces (Table 1). One may thus suggest that, when comparing saline and room-air features, the saline solution promotes intergranular fracture. At this stage, it is worth noting here that the dominant occurrence of intergranular fracture in zirconia agrees with the results of Okabe et al. [24], although the authors did not elaborate extensively on the fractographic aspects of their work, nor did they specify where the pictures were taken on the fracture surface, unlike in the present work.

This study is specific in terms of implant geometry and test atmospheres. It is believed that the implant geometry does not detract from the generality of the observations reported here. By contrast, simulated intraoral atmospheres, other than the saline solution might have their own different "signature", but it is believed that the methodology exposed in this work, namely establishment of a table similar to Table 1, could serve as a guideline for future studies of the fracture of ceramic (zirconia) biomedical structures.

Finally, answering the above two questions, this study shows that fatigue and monotonic fracture can be identified through the different combination of inter. and transgranular fracture at the origin. Likewise, concerning fatigue failure, it appears that the saline solution promotes intergranular fracture both at the crack origin and far away from it.

\section{CONCLUSIONS}

A systematic campaign of laboratory controlled fracture experiments of Y-TZP dental implants has been conducted.

From the thorough examination of the implants and their fracture surfaces it appears that:

- Every implant has superficial defects that may act as stress raisers.

- Every fracture comprises its own specific blend of inter. and transgranular fracture

- Two regions of interest can be distinguished: Crack origin and farther away corresponding to unstable crack growth. 
- Quasi-static fracture in either room air or saline solution yields a similar blend of trans. and intergranular fracture, rendering differentiation almost impossible. A clear evolution from trans. to intergranular fracture can be observed in both cases.

- Spectrum fatigue fracture, in room air can be differentiated fractographically from that in saline solution, and also from static fracture.

- For fatigue spectrum loading in both atmospheres, the tendency for intergranular fracture increases along the crack propagation path, starting from mostly transgranular.

- Saline solution seems to promote intergranular fracture.

\section{Acknowledgement}

This research did not receive any specific grant from funding agencies in the public, commercial, or not-for-profit sectors.

Dr. Noran de Basso is kindly acknowledged for providing the ceramic implants characterized in that study. A. Godinger and J.C. Nieto Fuentes' help with the SEM is greatly appreciated. The authors acknowledge many fruitful discussions with Prof. S. Osovski, and Dr. A. Dorogoy for performing the finite element calculations of this work. 


\section{REFERENCES}

[1] K. Mills, American Society for Metals., ASM Handbook Committee., Fractography, ASM International, 1987. https://www.asminternational.org/search/-

/journal_content/56/10192/06365G/PUBLICATION (accessed June 26, 2018).

[2] W.T. Becker, R.J. Shipley, ASM Handbook: Failure Analysis and Prevention, n.d. www.asminternational.org (accessed June 26, 2018).

[3] G.D. Quinn, NIST Recommended Practice Guide: Fractography of Ceramics and Glasses, Natl. Inst. Stand. Technol. NIST Recomm. 191 (2007). doi:10.6028/NIST.SP.960-16e2.

[4] B.R. Lawn, Fracture of brittle solids, Cambridge University Press, 1993.

[5] S.S. Scherrer, G.D. Quinn, J.B. Quinn, Fractographic failure analysis of a Procera ${ }^{\circledR}$ AllCeram crown using stereo and scanning electron microscopy, Dent. Mater. 24 (2008) 1107-1113. doi:10.1016/j.dental.2008.01.002.

[6] S.S. Scherrer, J.B. Quinn, G.D. Quinn, J.R. Kelly, Failure analysis of ceramic clinical cases using qualitative fractography., Int. J. Prosthodont. 19 (2006) 185-92. http://www.ncbi.nlm.nih.gov/pubmed/16602369.

[7] S.S. Scherrer, J.B. Quinn, G.D. Quinn, H.W.A. Wiskott, Fractographic ceramic failure analysis using the replica technique, Dent. Mater. 23 (2007) 1397-1404. doi:10.1016/j.dental.2006.12.002.

[8] J.B. Quinn, G.D. Quinn, J.R. Kelly, S.S. Scherrer, Fractographic analyses of three ceramic whole crown restoration failures, Dent. Mater. 21 (2005) 920-929. doi:10.1016/j.dental.2005.01.006.

[9] U. Lohbauer, G. Amberger, G.D. Quinn, S.S. Scherrer, Fractographic analysis of a dental zirconia framework: A case study on design issues, J. Mech. Behav. Biomed. Mater. 3 (2010) 623-629. doi:10.1016/j.jmbbm.2010.07.004.

[10] R. Belli, S.S. Scherrer, S. Reich, A. Petschelt, U. Lohbauer, Case Studies in Engineering Failure Analysis In vivo shell-like fractures of veneered-ZrO 2 fixed dental prostheses, Biochem. Pharmacol. 2 (2014) 91-99.

doi:10.1016/j.csefa.2014.06.001.

[11] S.S. Scherrer, U. Lohbauer, A. Della Bona, A. Vichi, M.J. Tholey, J.R. Kelly, R. van Noort, P.F. Cesar, ADM guidance-Ceramics: guidance to the use of fractography in failure analysis of brittle materials, Dent. Mater. 33 (2017) 599-620. doi:10.1016/j.dental.2017.03.004.

[12] M. Øilo, D. Arola, Fractographic analyses of failed one-piece zirconia, Dent. Mater. (2018) 1-10. doi:10.1016/j.dental.2018.03.018.

[13] S. Fraga, G.K.R. Pereira, M. Freitas, C.J. Kleverlaan, L.F. Valandro, L.G. May, Loading frequencies up to $20 \mathrm{~Hz}$ as an alternative to accelerate fatigue strength tests in a Y-TZP ceramic, J. Mech. Behav. Biomed. Mater. 61 (2016) 79-86. doi:10.1016/j.jmbbm.2016.01.008.

[14] C. Oblak, A. Kocjan, P. Jevnikar, T. Kosmac, The effect of mechanical fatigue and accelerated ageing on fracture resistance of glazed monolithic zirconia dental bridges, J. Eur. Ceram. Soc. 37 (2017) 4415-4422. doi:10.1016/j.jeurceramsoc.2017.04.048.

[15] C.P. Zucuni, L.F. Guilardi, M.P. Rippe, G. Kalil, R. Pereira, L.F. Valandro, Author ' s Accepted Manuscript processing treatments, J. Mech. Behav. Biomed. Mater. (2017). doi:10.1016/j.jmbbm.2017.06.016.

[16] D. Burtscher, I. Grunert, H. Kniha, E. Steinhauser, Failure analysis of fractured dental zirconia implants, (2011) 287-293. doi:10.1111/j.1600-0501.2011.02206.x.

[17] R.H. Dauskardt, W.C. Carter, D.K. Veirs, R.O. Ritchie, Transient subcritical crack- 
growth behavior in transformation-toughened ceramics, Acta Metall. Mater. 38 (1990) 2327-2336. doi:10.1016/0956-7151(90)90099-3.

[18] L. Ewart, S. Suresh, Crack propagation in ceramics under cyclic loads, J. Mater. Sci. 22 (1987) 1173-1192. doi:10.1007/BF01233107.

[19] S. - Y Liu, I. -W Chen, Fatigue of Yttria-Stabilized Zirconia: I, Fatigue Damage, Fracture Origins, and Lifetime Prediction, J. Am. Ceram. Soc. 74 (1991) 1197-1205. doi:10.1111/j.1151-2916.1991.tb04088.x.

[20] S. Liu, I. Chen, Fatigue of Yttria-Stabilized Zirconia: II, Crack Propagation, Fatigue Striations, and Short-Crack Behavior, J. Am. Ceram. Soc. 74 (1991) 1206-1216.

[21] A.G. Evans, Fatigue in ceramics, Int. J. Fract. 16 (1980) 485-498. doi:10.1007/BF02265214.

[22] R.O. Ritchie, Fatigue of Brittle Materials, Compr. Struct. Integr. 4 (2003) 359-388. doi:10.1361/asmhba0002417.

[23] J.D. Landes, A Two Criteria Statistical Model for Transition Fracture Toughness, Fatigue Fract. Eng. Mater. Struct. 16 (1993) 1161-1174. doi:10.1016/00343617(91)90281-3.

[24] T. Okabe, T. Miyahaba, Fatigue fracture behavior of oxide ceramics in water, 48 (1994) 137-146.

[25] E.C. Panagiotopoulos, A.G. Kallivokas, I. Koulioumpas, D.E. Mouzakis, Early failure of a zirconia femoral head prosthesis: Fracture or fatigue?, Clin. Biomech. 22 (2007) 856-860. doi:10.1016/j.clinbiomech.2007.04.007.

[26] K. Shemtov-Yona, D. Rittel, Identification of failure mechanisms in retrieved fractured dental implants, Eng. Fail. Anal. 38 (2014) 58-65.

doi:10.1016/j.engfailanal.2014.01.002.

[27] K. Shemtov-Yona, D. Rittel, Random spectrum loading of dental implants: An alternative approach to functional performance assessment, J. Mech. Behav. Biomed. Mater. 62 (2016) 1-9. doi:10.1016/j.jmbbm.2016.04.030.

[28] ISO, ISO 14801:2016(en), Dentistry — Implants — Dynamic loading test for endosseous dental implants, 2016. https://www.iso.org/obp/ui/\#iso:std:iso:14801:ed3:v1:en (accessed February 10, 2017).

[29] K. Shemtov-Yona, D. Rittel, Fatigue of Dental Implants: Facts and Fallacies, Dent. J. 4 (2016) 16. doi:10.3390/dj4020016.

[30] K. Shemtov-Yona, D. Rittel, Fatigue failure of dental implants in simulated intraoral media, J. Mech. Behav. Biomed. Mater. 62 (2016) 636-644. doi:10.1016/j.jmbbm.2016.05.028.

[31] K.B. Broberg, Cracks and fracture, Academic Press, San Diego, 1999.

[32] W.G. Knauss, K. Ravi-Chandar, Some basic problems in stress wave dominated fracture, Int. J. Fract. 27 (1985) 127-143.

[33] Abaqus, Finite Element Package (explicit), v6, 14-2, (2014).

[34] T.L. Anderson, Fracture Mechanics: Fundamentals and Applications, CRC Press, 1995. 


\section{Appendix 1}

\begin{tabular}{|c|c|c|c|c|c|}
\hline Element & $\begin{array}{c}\mathrm{ZrO}_{2}+\mathrm{HfO}_{2+} \\
\mathrm{Y}_{2} \mathrm{O}_{3}\end{array}$ & $\mathrm{Y}_{2} \mathrm{O}_{3}$ & $\mathrm{HfO}_{2}$ & $\mathrm{Al}_{2} \mathrm{O}_{3}$ & $\begin{array}{c}\text { Other oxides } \\
\text { Total }\end{array}$ \\
\hline wt \% & 99.35 & 5.73 & 1.46 & 0.33 & 0.32 \\
\hline
\end{tabular}

Table A1: Composition of the Y-TZP implants (spectrometric analysis provided by the manufacturer) 


\section{Appendix 2}

\begin{tabular}{|c|c|c|c|c|}
\hline $\begin{array}{c}\text { Specimen } \\
\text { number }\end{array}$ & Test & $\begin{array}{c}\text { Nominal } \\
\text { time to } \\
\text { failure } \\
{[\mathbf{s}]}\end{array}$ & $\begin{array}{c}\text { Fracture } \\
\text { Load } \\
{[\mathbf{N}]}\end{array}$ & $\begin{array}{c}\text { Total } \\
\text { \# cycles }\end{array}$ \\
\hline c1 & Static air & & 660 & \\
\hline c3 & & 941 & \\
\hline c4 & air & 2967 & 538 & 4046 \\
\hline c13 & $\begin{array}{c}\text { Spectrum } \\
\text { air }\end{array}$ & 17490 & 545 & 22863 \\
\hline c15 & 17439 & 471 & 22786 \\
\hline c20 & Static & 1451 & 572 & 2218 \\
\hline c36 & saline & 663 & \\
\hline c37 & & 11932 & 553 & 15714 \\
\hline c38 & & & 672 & \\
\hline c39 & $\begin{array}{c}\text { Spectrum } \\
\text { saline }\end{array}$ & 1448 & 573 & 2210 \\
\hline c45 & & 2975 & 538 & 4070 \\
\hline c51 & & 117 & 564 & \\
\hline
\end{tabular}

Table A2: Details of all the representative specimens selected for SEM examination. For the quasi-static tests, only the fracture load is mentioned. For the spectrum tests, both fracture load and total number of cycles to fracture is mentioned. 


\section{Appendix 3: A fracture mechanics estimation of the critical crack size}

We consider a cylindrical pole, $12.5 \mathrm{~mm}$ high and $3.5 \mathrm{~mm}$ in diameter. The pole contains a basal crack (at $\mathrm{h}=0$ ) whose upper face is traction free, bottom face is constrained and the lower ligament is assumed to be fully constrained. On the top of the pole, a $100 \mathrm{~N}$ load is applied at a $30^{\circ}$ angle. The stress intensity factor (SIF) is calculated at the middle of the crack tip line (Fig. A1a) where it is assumed that plane-strain conditions prevail (Figure A1).

$$
\begin{aligned}
& P=F \cos (\theta) \\
& Q=F \sin (\theta) \\
& M=F \sin (\theta) H
\end{aligned}
$$
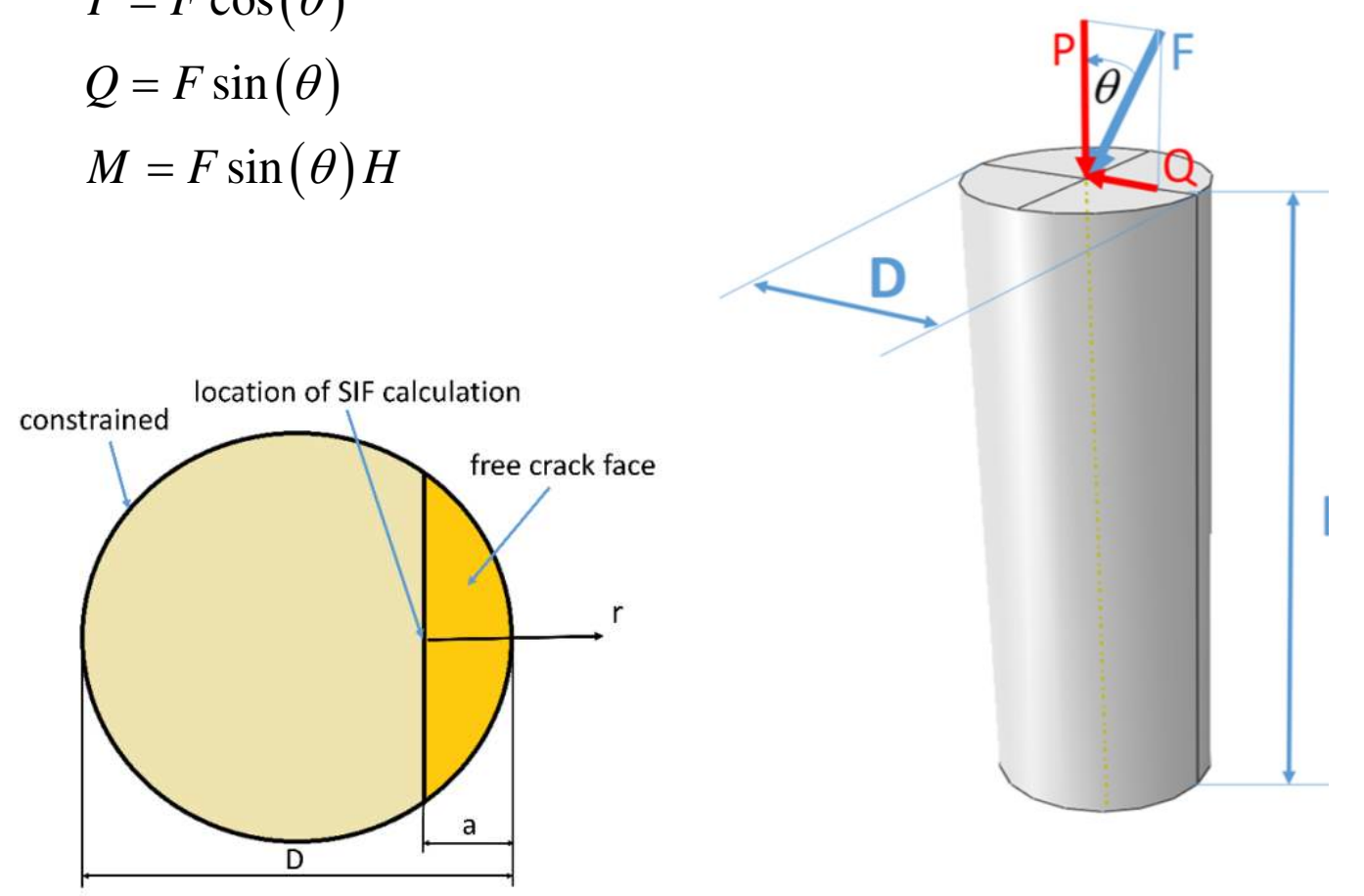

a.

b.

Figure A1: Model for calculation of the stress intensity factor of a basal crack in a cylindrical ceramic pole under bending loads. a: Bottom half-constrained crack, and b: The loaded pole, representing a dental implant is made of Zirconia with a Young's modulus E=200 GPa and Poisson's ratio $v=0.31$.

The finite element model is solved using Abaqus Standard [33] assuming a linear elastic material model. The element type is linear hexahedron, type C3D8R with a typical size near the crack-tip of $0.25 \mathrm{~mm}$.

Figure A2 shows the calculated dependence of the stress intensity factor upon the crack's relative depth. The SIF is calculated from the upper crack face displacement along the coordinate $\mathrm{r}$ (Fig. A1a) by fitting the numerical normal gaps to the expression [34]: 


$$
\Delta U_{y}(r)=U_{y}(r, \pi)-U_{y}(r,-\pi)=\sum_{i=0}^{n} a_{i} r^{i+0.5}
$$

The SIF is calculated from a0 (singular term) by:

$$
K_{I}=\frac{a_{0}}{\beta}
$$

Where $\beta=\frac{(\kappa+1)}{G \sqrt{2 \pi}}$. The shear modulus is given by: $G=\frac{E}{2(1+v)}$ and $\kappa=3-4 v$ in plane strain.

The SIF of Fig. A2 can be cast into the form (A3):

$$
K_{I} \approx \frac{F}{\left(\frac{\pi D^{2}}{4}\right)} Y \sqrt{\pi a}
$$

In which the various variables are shown in Figure $A 1$, and $Y$ is the crack shape factor, $f(a / D)$.

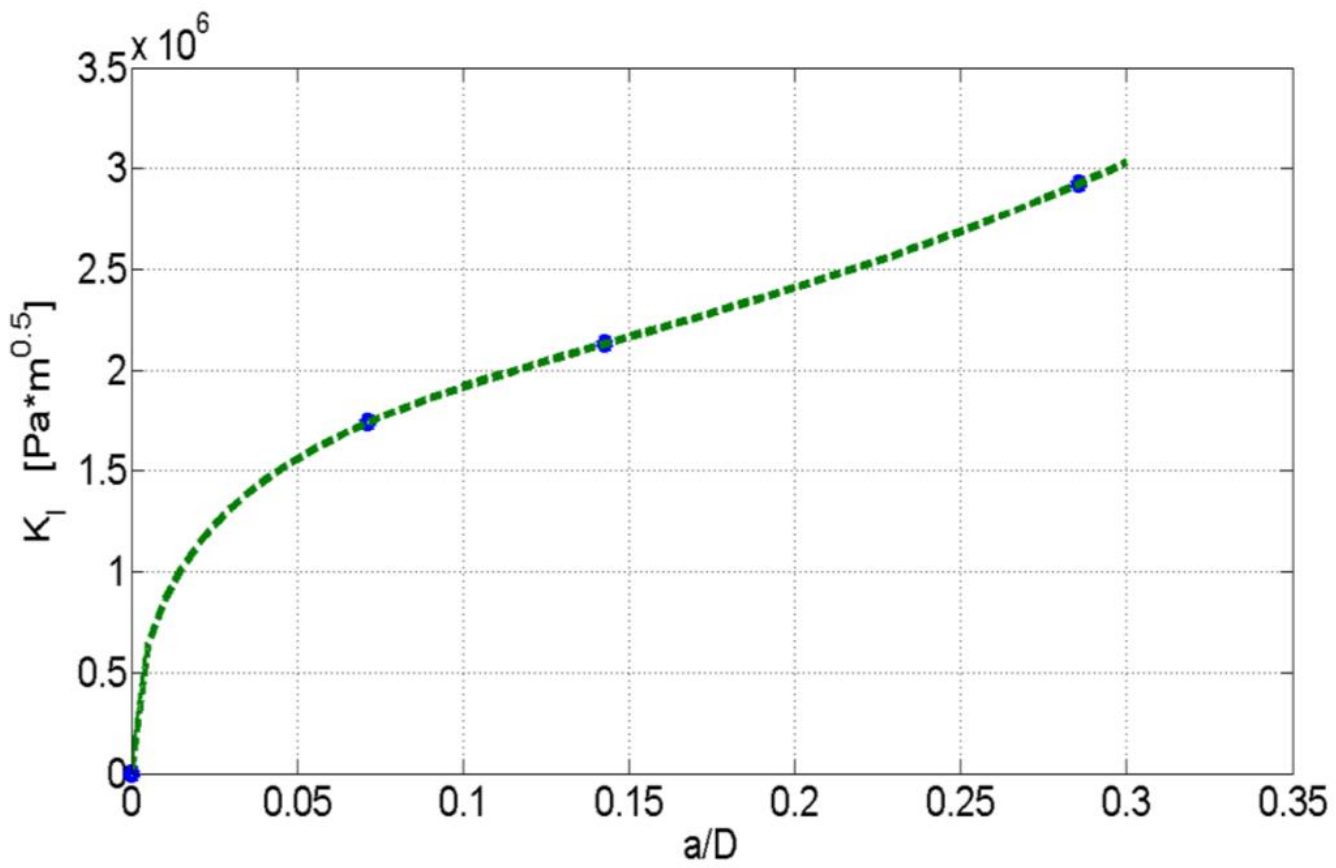

Figure A2: Stress intensity factor versus a/D.

The crack shape factor $\mathrm{Y}$ is shown in Figure A2 as a function of the crack's relative depth. 


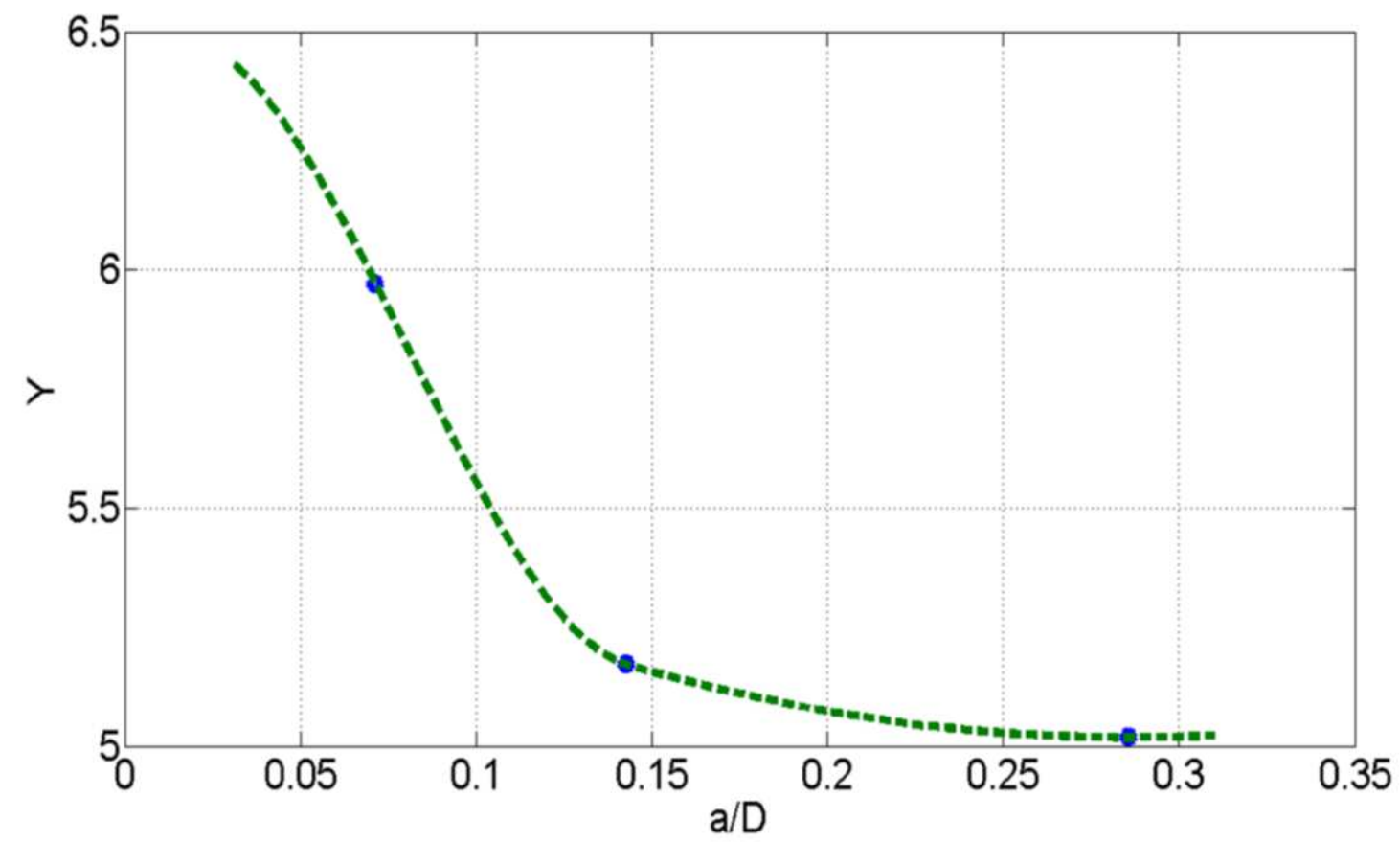

Figure A3: The non-dimensional crack shape factor $\mathrm{Y}$ versus a/D.

For short cracks, Figure A3 shows that $\mathrm{Y} \approx 6.5$. Assuming that $\mathrm{K}_{\mathrm{Ic}}$ is $5.5 \mathrm{MPa} \mathrm{m}_{1 / 2}$, and substituting a typical value of the fracture load F=600 N in Eqn. (A1), one obtains the following estimation for a short crack: $\mathbf{a}(\mathbf{Y}=\mathbf{6 . 5})=\mathbf{5 9} \boldsymbol{\mu m}$. 